\title{
On English Translatability Limits of Dress Culture in A Dream of Red Mansions
}

\section{Shen Huijia}

School of Foreign Languages, Dongfang College, Zhejiang University of Finance and Economics, Haining, China.

\begin{abstract}
A Dream of Red Mansions, known as the "Encyclopaedia of Chinese culture", is the pinnacle of Chinese classical literature. Based on the analysis of translation of different dresses in A Dream of Red Mansions by Mr Yang Xianyi and his wife Glaydis Yang, this paper discusses the limits of cultural translatability of dress colours, materials, styles, accessories and patterns, and put forward some complementary translation methods, such as literal translation with explanation, free translation, corresponding translation, rewriting, transliteration. It can be seen that although there are limits of translatability in the original text in some cases, the untranslatability can be transformed to translatability to the maximum extent by using flexible translation methods.
\end{abstract}

Keywords-A Dream of Red Mansions; dress culture; limits of translatability; culture connotation; translation methods.

\section{INTRODUCTION}

With the implementation of Chinese culture's "Going Out" strategy, Beijing Opera, Chinese movie and drama, classics and other excellent Chinese cultures are stepping up to the world, which has become a better way to enhance the national cultural soft power. As a bright pearl in Chinese classical literature, A dream of Red Mansions enjoys the reputation of "Encyclopaedia of Chinese culture". Due to its unique charm, it has attracted many researchers and has become a school of "Redology". Dress culture in this masterpiece also attracts great attention. The dresses of the characters in this works contain rich cultural contents. This paper selects the most representative translation of A Dream of Red Mansions by Mr Yang Xianyi and his wife Glaydis Yang as an example, analyzes the translation of dress colours, materials, styles, accessories and patterns from the perspective of culture, and then discusses the translatability limits of dress culture, as well as put forward some complementary translation methods to better promote the overseas communication of Chinese traditional dress culture.

\section{AN INTRODUCTION TO LIMITS OF TRANSLATABILITY}

The limits of translatability refer to the possibility of translation from one language to another, that is, under what circumstances it is translatable and what is untranslatable. To be specific, apart from the generality, there are still great differences among different languages, not only the differences in pronunciation, spelling and grammar, but also the differences in expressions and language habits such as words, metaphors and associations. Therefore, it is very difficult or even impossible to transplant the contents, thoughts and feelings expressed in the original text into the translated text, which leads to the problem of translatability limitation. "Translation is impossible" has been repeatedly mentioned in translation theories in recent decades, and has been analyzed and demonstrated at the theoretical level. Even the translation theorists represented by Whorf, B.L. (1956) in the United States have come to the conclusion that untranslatability is absolute. However, the French translation theorist Georges Mounin (1963:143) made a deep study on the translatability of translation in his book 
Theoretical Problems of Translation, and put forward the view that "translation is possible, but it is limited". The English linguist Catford (1965) distinguishes linguistic untranslatability from cultural untranslatability and attempts to incorporate cultural untranslatability into linguistic untranslatability. Chinese Professor $\mathrm{Xu}$ Jun (2009:65) of Nanjing University, after sorting out the discussions of translation theorists and philosophers on untranslatability and translatability, has come to the conclusion that "translation is feasible, but there are certain limitations, especially in cultural translation". The following will take the translation of dresses in A Dream of Red Mansions as an example.

\section{The Limits of Translatability in Dress Culture-With} Special Reference to the English Version of $A$ Dream of Red Mansions

As a carrier of culture, dress reflects rich national and social cultural connotation, and embodies custom, moral etiquette, hierarchical status, aesthetic taste, belief and etiquette signs of different times. The five elements of dress refer to the colour, material, style, accessory and pattern. These five elements can reflect the social and cultural connotation of dress, and reflect the dignity and status of a person. The author Cao Xueqin lived in the noble family of Qing Dynasty when he was young. He was very familiar with the dress of Qing Dynasty and had a unique and deep understanding of the dress culture. We can have a glimpse of the general situation of Chinese dress in Qing Dynasty from his works. In A Dream of Red Mansions, there are hundreds of descriptions about dresses, of which there are many styles, rich colours and complicated patterns. From the master to the young lady, to the servant, the dress of Jia's family varies according to the individual's social status and preferences. This paper discusses the translation of some representative dresses and reveals the limits of cultural translatability according to the five elements of dresses.

\subsection{The Limits of Cultural Translatability of Dress Colours}

The dress colours in A Dream of Red Mansions are magnificent and varied. "Yellow" has always been regarded as respecting colour in Chinese traditional culture, which symbolizes holiness and dignity. Since yellow belongs to the colour of emperors, everything related to emperors in ISSN: 2456-7620 social life is yellow. For example,

Example1：一队队过完, 后面方是八个太监抬着 一顶金顶金黄秀凤版舆, 缓缓行来。贾母等连忙路边踠 下。( in Chapter 18)

The Yangs' Version : Last of all, borne slowly forward by eight eunuchs, came a gold-topped palanquin embroidered with phoenixes. All present, including the Lady Dowager, hastily fell to their knees by the side of the road.

Jia Baoyu's grandma, Lady Dowager is the most important person in Ning and Rong's two families in $\boldsymbol{A}$ Dream of Red Mansions. However, when she saw "a golden top a gold-topped palanquin embroidered with phoenixes" (the sedan chair in which the imperial concubine was sitting), she also knelt down on the roadside to show her respect. Mr Yang Xianyi and his wife Glaydis Yang translated “金顶金黄” into "gold-topped". Although it conveys the literal meaning, the cultural image caused by "yellow" no longer exists. Foreign readers cannot understand the conceptual culture reflected by "yellow" here, which fully proves the existence of translatability limit. In the west, purple symbolizes nobility and imperial power, so here we can use domestication to translate “金顶金黄” into "Purple-topped" and the target language will be understandable. In Example 1, translatability limits can be reduced by corresponding translation because the deep meanings of colour words are basically equivalent between Chinese and Western culture.

Example2 : 宝玉见黛玉时, 黛玉腰下系着一条杨 妃色绣花棉裙, 浑身打扮得雅致素净, 别有一番动人风 姿。（in Chapter 89)

The Yangs' Version : ..., a pink embroidered silk padded skirt of the kind worn by Lady Yang.

According to Imperial Concubine Yang, Emperor Xuanzong of Tang Dynasty used the colour of Begonia to describe Lady Yang's face after she was drunk, so "Lady Yang's colour" should be the colour of Begonia. The translated version is obviously incorrect. If "Lady Yang's colour" is translated into Begonia red, the meaning of the original text is correctly conveyed. However, its cultural background cannot be well 
expressed, which inevitably leads to the loss of information. So it can be annotated because it is difficult to find "equivalent" words in the target language with great differences in cultural background. In order to retain the national characteristics and images of the original text, especially allusions with special meanings are often translated literally with explanation, so as not to make readers confused.

2.2 The Limits of Cultural Translatability of Dress Materials

The quality of dress materials will not only affect the quality and beauty of clothing, but also highlight the cultural connotation of clothing. Those who wear linen and coarse clothes are poor, while those who wear silk and satin are rich.

Example 3 : 这是两个茧绸, 作袄儿裙子都好。( in Chapter 42)

The Yangs' Version : These two rolls of raw silk would do well for tunics or skirts.

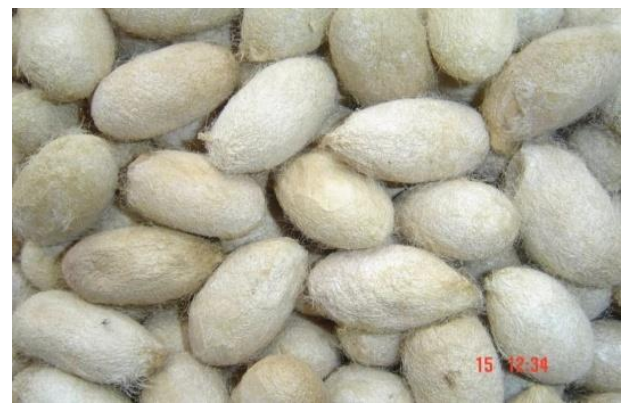

Fig.1：虫茧

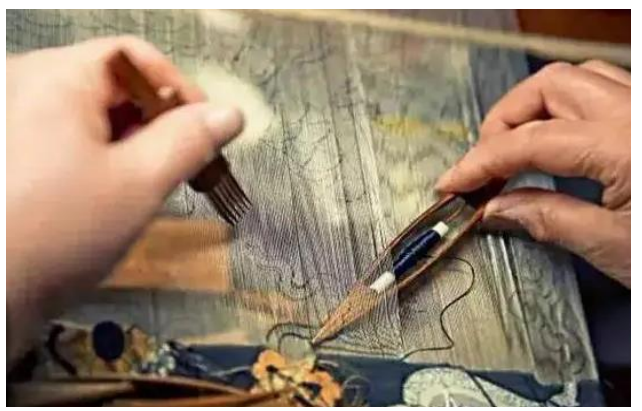

Fig.2：茧绸

Lady Pinger gave grandma Liu many presents, including some cloth and dresses. In the Qing Dynasty, silk ISSN: 2456-7620 was a common dress material. "Cocoon silk" refers to pongee or tussah silk. It is difficult for westerners to understand "cocoon silk", so the Yangs translated it as "raw silk", which can strengthen westerners" understanding of Chinese dress culture. The translators adopted corresponding translation, making it more easily understood by Westerners. They adjust the translation methods appropriately according to the context of specific text. Therefore, the original meaning and connotation could be explained, equivalent words between Chinese and Western culture could be found, and the culture words with Chinese characteristics can be translated to the Western countries in the highest degree.

Example 4: 宝玉此时欢喜非常, 忙唤人来, 貲洗 已毕, 只穿一件茄色哆罗呢狐皮袄子, ...... (in Chapter 49)

The Yangs' Version : In high delight he called for someone to help him with his toilet. Wearing just his purple velvet gown lined with fox-fur, and....

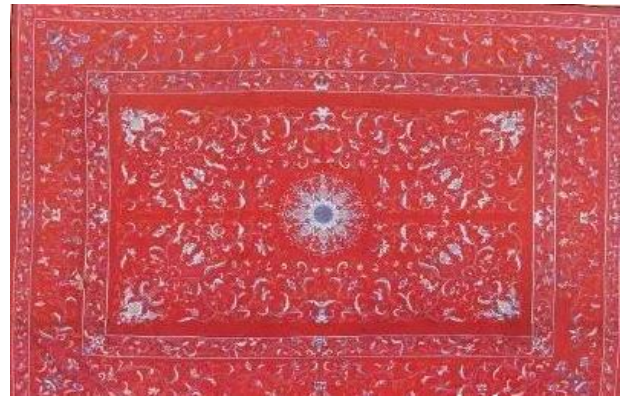

Fig.3. 哆罗呢

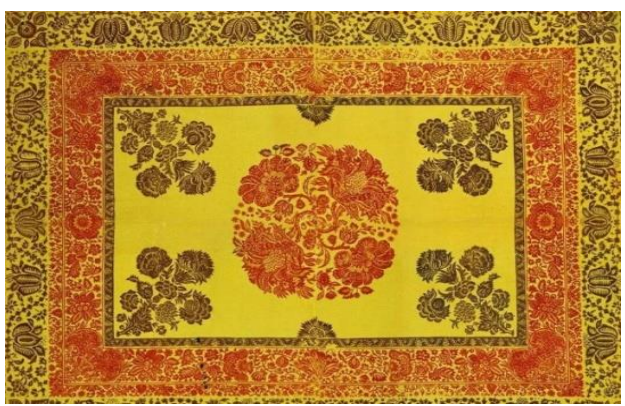

Fig.4. 哆罗呢

In the early Qing Dynasty, when the envoys of 
Western European countries came to China, they often presented “哆罗呢” to the Qing emperor. In the Yangs' translation, “哆罗呢” is translated into "velvet”, while in The New Oxford English-Chinese Dictionary, the interpretation of "velvet" is "a fine closed woven material made of silk, nylon, cotton, etc., with a soft fur surface on one side only". This is different from the original “哆罗呢” in terms of material. “Woollen" means plush and fabric, which is the same material as " 哆罗呢”. And it is an imported product, the word "foreign" can be added before "woollen" to reflect that this kind of dress material was imported from abroad, and readers can understand that it is high-quality woollen cloth at the same time. The application of dress materials reflects the development and civilization of a nation's printing and dyeing technology. The dress materials in $A$ Dream of Red Mansions reflect the aesthetic outlook of Qing Dynasty clothing and textile printing and dyeing technology, as well as the status of different characters in Jia's mansion.

It can be seen that although there is a limit of cultural translatability, the translator can take some appropriate methods according to different contexts. He can not only translate the meaning and connotation of the original text, but also try his best to find equivalent words between Chinese and Western cultures, so as to translate the words with Chinese cultural connotation to the west as much as possible.

\subsection{The Limits of Cultural Translatability of Dress Styles}

In A Dream of Red Mansions, the description of the characters' clothes is quite detailed and authentic. Different characters have different styles of clothes. "袄" is one of the most frequently used dressing styles. Its styles are changeable, including long style, medium length style and short style. As a kind of home-made casual clothes, "袄” is often worn by the masters and servants of Daguan garden. Among them, there are seven kinds of “袄” that Jia Baoyu often wears, and Wang Xifeng wears four kinds of “袄”.

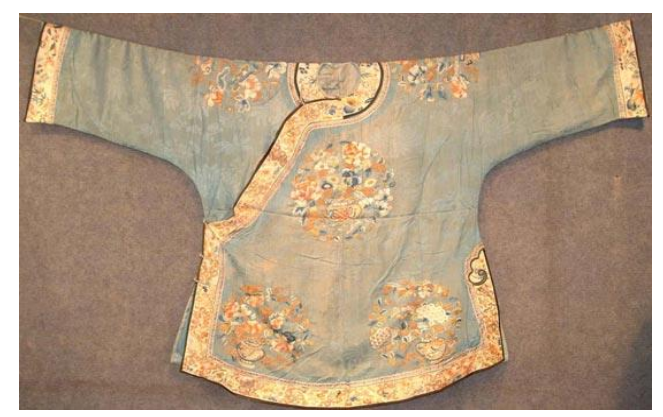

Fig.5: 袄

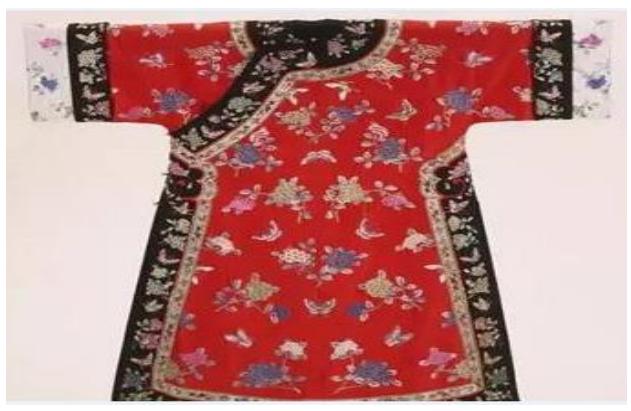

Fig.6: 袄

Example 5：（宝玉）穿着大红棉纱小袄子，下面 绿绫弹墨夹裤。（in Chapter 63）

The Yangs' Version : Baoyu himself stripped down to a scarlet linen jacket and green dotted stain trousers...

Example 6：（王熙凤）身上穿着缕金百蝶穿花大 红洋䌸窄褃袄。（in Chapter 3)

The Yangs' Version : Her close-fitting red satin jacket was embroidered with gold butterflies and flowers.

Example 7 : (众人) 身上皆是长裙短袄。（in Chapter 63)

The Yangs' Version : ...Wearing only long skirts and bodices.

The Yangs translated "袄" into "jacket" or "bodices". Jacket refers to a short coat. Bodice's interpretation in the dictionary is "the part of woman's dress (excluding sleeves) which is above waist." It is totally inconsistent with the shape and style of "袄". Therefore, the Yangs' translation can not reflect the basic characteristics of the "袄" —right placket, slit on sides, stand collar, raglan sleeves, etc. Although they 
cater to the reading habits of foreign readers, they do not have the unique charm of Chinese clothes. The style of the "袄" is changeable, with various colours and lengths. Just like the Western T-shirt, its styles and colours vary greatly. Whether it is long, short, loose, tight, knitted, woven, chemical fibber or cotton, linen and wool, it is collectively referred to T-shirt in China. So “袄” should also have a general name with distinctive Chinese characteristics in foreign language. As we can see from the analysis above, translatability can be developed to the largest extent in a better way. At present, it is more appropriate to use transliteration method to translate "袄" into "Chinese-ao". The combination of Chinese Pinyin and English not only shows that it is a unique Chinese dress, but also is conducive to the recognition of Westerners.

“箭袖” appeared five times in the first 80 chapters of $A$ Dream of Red Mansions. They are all worn by Baoyu. Each “箭袖” has gorgeous materials and rich colours. “箭袖” is a kind of robe with arrow sleeve which is convenient to shoot arrows. It tacks a semicircular "sleeve" on the narrow cuff, and it is shaped like a horse's hoof. In Manchu, it is called "waha", commonly known as horse-hoof sleeve, originated from northern ethnic costumes.

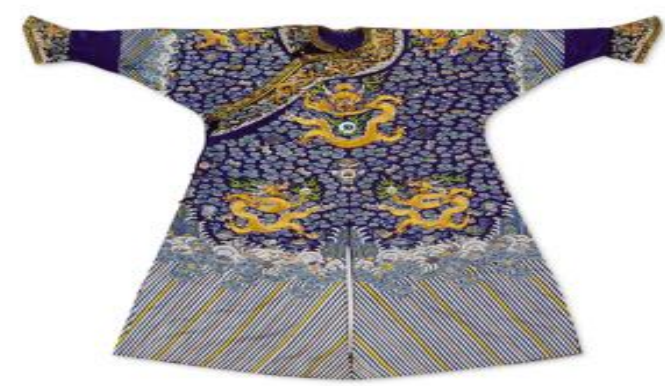

Fig.7: 箭袖

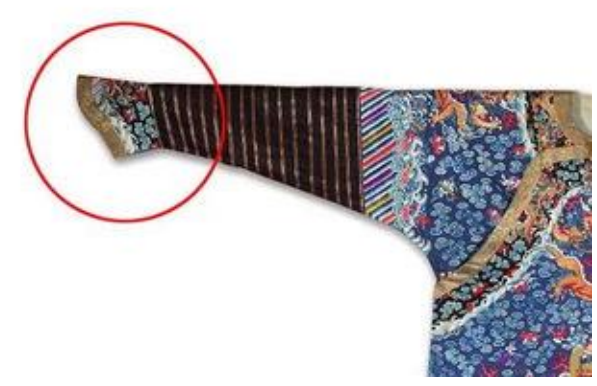

Fig.8：劄袖
Example 8: 二色金百蝶穿花大红箭袖。（in Chapter 3)

The Yangs' Version : His red archer's jacket, embroidered with golden butterflies and flowers.

Example 9: 大红金蟒狐腋箭袖。（in Chapter 19 )

The Yangs' Version : His red archer's tunic embroidered with golden dragons...

Example 10 : 茄色哆罗呢的天马箭袖。（in Chapter 52)

The Yangs' Version : His brown velvet archer's coat lined with fox fur...

“箭袖" is a image which is full of traditional Chinese cultural character and symbolic meaning. Because this image does not exist in Western dress culture and does not have equivalent word in English, the translator should make a choice in translating process. With strong Chinese traditional clothing characteristics, the Yangs translated “箭袖" into "archer's jacket, archer's coat or archer's tunic". First of all, they affirmed that "箭袖" is a riding and shooting clothing, but it is obviously inappropriate to use three different words to translate the same dress. Moreover, it does not reflect its characteristics in terms of style and cultural connotation. So Wang Dianming and Yang Qihua, who have been engaged in English translation of cultural relics and museums for many years in the Beijing Palace Museum, used free translation method to translate the "箭袖" into "Horsehoof- shaped cuff".

Classic works like A Dream of Red Mansions carries deep Chinese culture. Therefore, the translator should not only have a correct understanding of Chinese dress culture, but also focus on conveying the cultural connotation faithfully and accurately. Due to the great cultural differences between China and the West, translators should overcome the barriers of cultural differences and promote the communication between Chinese and Western cultures with accurate understanding, clear purpose and proper methods.

2.4 The Limit of Cultural Translatability of Dress Accessories

The accessory in A Dream of Red Mansions is an epitome of 
traditional Chinese ornaments. In this works, there are many kinds of accessories which not only play the role of decoration, but also contain specific social feelings and cultural consciousness. Those accessories mainly include “ 昭君套”, “抹额”, “观音兒”, “荷包”, “䯽”, “扇囊”, etc. This paper analyzes the translation of “昭君套”and “抹额”, which are full of Chinese traditional characteristics.

Example 11: 那凤姐儿家常带着秋板貂鼠昭君套 - (in Chapter 6)

The Yangs' Version : Xifeng had on the dark sable hood with a pearl-studded band which she wore at home.

Example 12 ：（史湘云）头上带着一顶挖云我鸟黄片 金里大红猩猩毡昭君套。（in Chapter 49）

The Yangs' Version : ..., a scarlet woolen hood with a gosling-yellow appliqué of cloud designs and a golden lining, and a big sable collar.

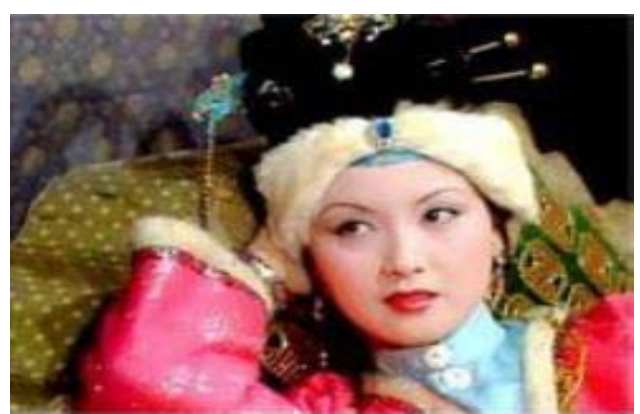

Fig.9：昭君套

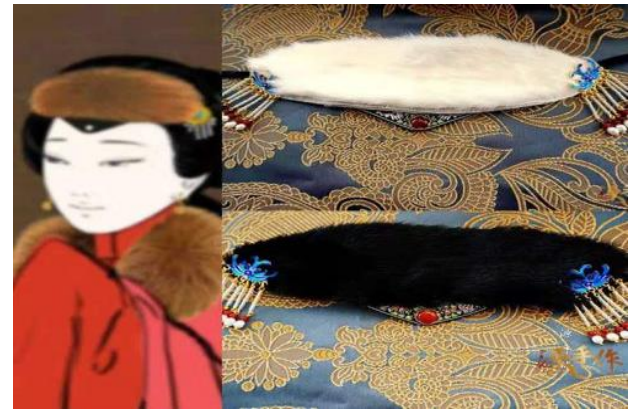

Fig.10：昭君套

“昭君套” is a kind of decoration on ancient women’s head, with striped mink around the forehead, like a cap sleeve. It is said that it was worn by Wang Zhaojun when she left the frontier, so it is called “昭君套”. The Yangs translated it as "hood", which means "A covering for ISSN: 2456-7620 the head and neck with an opening for the face, typically forming part of a coat or cloak." in Oxford Advanced Learner's English-Chinese Dictionary. It is quite different from the traditional headdress “昭君套” in ancient China. Due to the untranslatability of culture, it could be translated into "Zhao Jun styled hood (Wang Zhaojun is the best known of China's political brides and the four beauties of ancient China)". The transliteration method of Chinese Pinyin with explanation can fully reflect the characteristics of Chinese traditional culture.

Example 13 ：（宝玉）齐眉勒着二龙抢珠金抹额。 (in Chapter 3)

The Yangs' Version : ...a golden coronet studded with jewels and a golden chaplet in the form of two dragons fighting for a pearl.

Example 14：（黛玉）将笠沿掖在抹额之上。（in Chapter 8)

The Yangs' Version : Baoyu went up to Daiyu, who put her hand gently over his coronet and placed the edge of the hood on his chaplet.

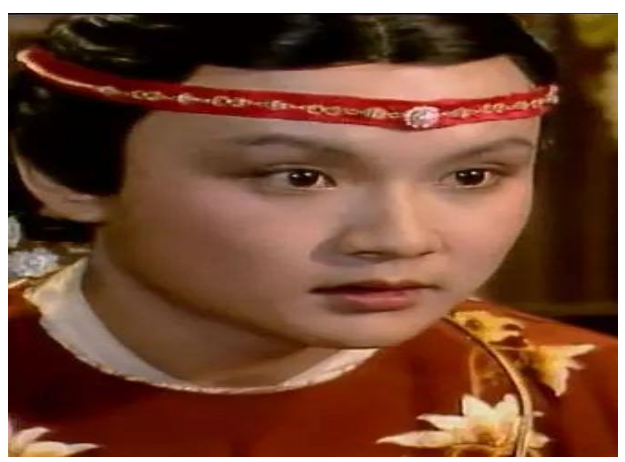

Fig.11：抹额

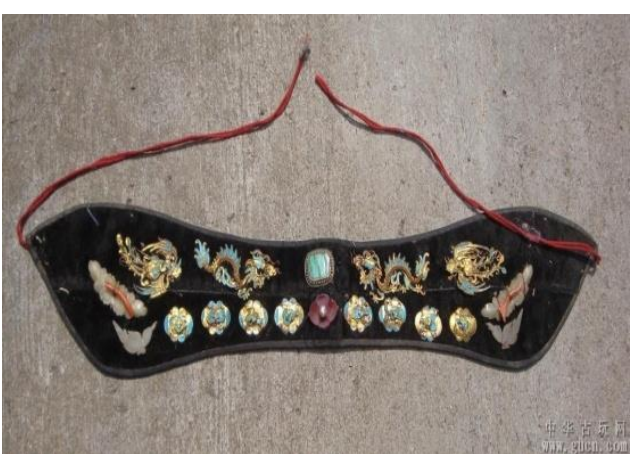

Fig.12: 抹额 
“抹额” is created by the northern ethnic minorities to protect them from the cold. It looks like a scarf tied on the forehead decorated with embroidery or pearl jade. Whether the designs on embroidery or inlaid with carved pearls and jades, they all focus on the beauty of symmetry and balance. The Yangs translated “抹额” into "chaplet", which is interpreted as "a garland or circle for a person's head." This explanation is similar to “抹额” in its function which is used for head decoration, but it does not reflect the formal aesthetic feeling of "symmetry and balance". This modelling feature reflects the cultural connotation of Chinese people's yearning for a happy life. The Yangs' translation is centred on original text which emphasizes the position and decorative role of “抹额”, but it fails to reflect the cultural characteristics of traditional Chinese clothing. This example fully reflects the untranslatability of culture. And appropriate translation methods are very useful to translate the accessories with different connotations. Rewriting is adopted to translate “抹额” into "chaplet low down over one's brow with symmetry and balance, which reflects Chinese people's yearning for a happy life."

\subsection{The Limit of Cultural Translatability of Dress Patterns}

Dress pattern refers to the regular decorative pattern of clothing and its accessories. The dress patterns in A Dream of Red Mansions are not only rich in cultural connotation, but also reflect the character's status, social system and traditional customs.

Example 15：（凤姐）项戴“赤金盘螭媞珞圈”。 in Chapter 3)

The Yangs' Version : Her necklet, of red gold, was in the form of a coiled dragon studded with gems.

Example 16：(宝玉) 项戴“金螭顼珞”。（in Chapter 3)

The Yangs' Version : Round his neck he had a golden torque in the likeness of a dragon.

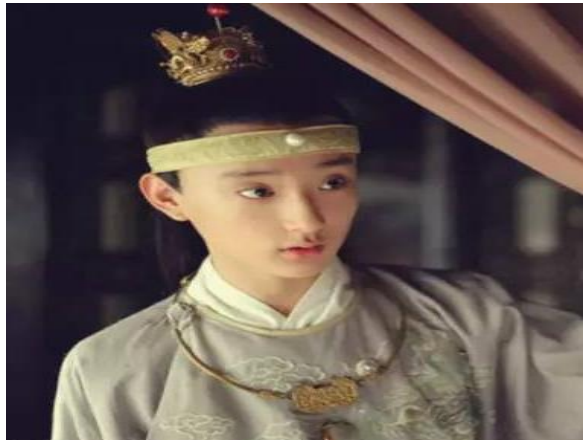

Fig.13：金螭璎珞

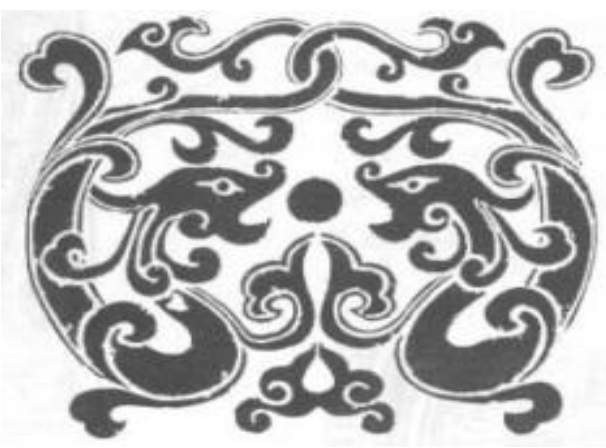

Fig.14：螭

As one of the forms of dragon pattern, “螭” is a hornless little dragon in ancient legends. Usually the zigzagging dragons circulate over and over again, which forms the “螭 纹'. In A Dream of Red Mansions, this pattern is also reflected in the clothing accessories. The Yangs translated “螭” into "dragon", but it is not in line with the shape of Chinese dragon. Therefore, the translation of "螭" may add the word "mulley" before "dragon", which not only differs from the common Chinese dragon, but also shows a good omen in Chinese culture.

Example 17 : (凤姐)身着“缕金百蝶穿花窄褃袄。 (in Chapter 3)

The Yangs' Version : Her close-fitting red satin jacket was embroidered with gold butterflies and flowers.

Example 18: （宝玉）“穿一件二色金百蝶穿花大 红箭袖”。（in Chapter 3)

The Yangs' Version : His red archer's jacket, embroidered with golden butterflies and flowers, was tied with a colored tasseled palace sash. 


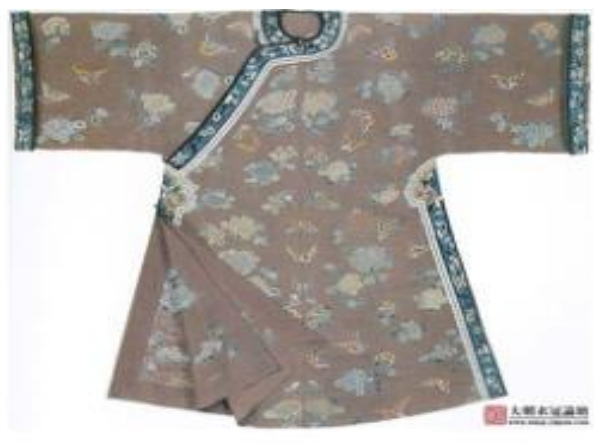

Fig.15: 百蝶穿花窄袒袄

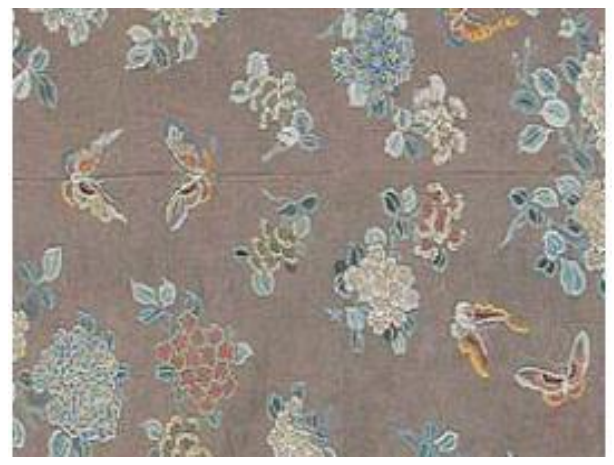

Fig.16：百蝶穿花纹

“百蝶穿花” is a pattern of flowers and butterflies interspersed and combined. Each unit of this pattern includes white plum blossom with pink blue branches, pink peach blossom, peony with blue flowers and green leaves, as well as Chinese roses, begonias, hibiscus and other flowers. These flower patterns with black hook edges are complex in shape and colour. Among them, more than 10 butterflies of different sizes and petals with gold thread are interspersed. This pattern is commonly used by nobles, such as Wang Xifeng and Jia Baoyu. It shows the luxury of their clothing and their noble status in the Jia family. The Yangs translated it into "embroidered with golden butterflies and flowers". Although it emphasizes the embroidery technology and pattern, it did not reflect the dynamic and artistic scene of butterflies flying and lingering on the flowers, as well as the cultural implication of beauty, auspiciousness, wealth and peace behind this scene. Therefore, the elegant pattern should be used free translation to translate into "embroidered with golden butterflies flying among flowers". The preposition "among" is more suitable than the conjunction "and", because "among" can cause readers to image the aesthetic and dynamic picture of many butterflies are flying cross beautiful flowers.

The detailed description of dress patterns in A Dream of Red Mansions shows the status, personality and Chinese traditional culture. The Yangs translated the characteristics of these patterns basically. Only when we are familiar with the connotations behind them can we have the most accurate translations.

\section{CONCLUSION}

As the encyclopaedia of Chinese culture, A Dream of Red Mansions has its own cultural deposits. Owing to the limitation of space, this paper only discusses these typical translation examples. From the above examples, we can see that words with strong cultural connotation are difficult to find their prototypes in the target culture, and their meanings are often not fully expressed in the translation. It is easy to cause the loss of part of the meaning, making the target readers unable to understand the original culture or the author's intention, which leads to the limits of cultural translatability. Due to the differences between Chinese and English cultures, the existence of translatability limits is an unavoidable reality in translation practice. The translator should understand the cultural connotation of the language deeply, and choose appropriate methods to reduce this limitation accurately and express the original content faithfully and smoothly. Through the analysis of the five translatability limits of dress culture in A Dream of Red Mansions by Mr Yang Xianyi and his wife Glaydis Yang, it can be seen that although there are limits of translatability in the original text in some cases, the untranslatability can be transformed to translatability to the maximum extent by using flexible translation methods, such as literal translation with explanation, free translation, corresponding translation, rewriting, transliteration, etc.. The study on translatability limits of dress culture will help the unique Chinese cultural treasure understood and appreciated in other countries in the world. 
International Journal of English Literature and Social Sciences, 5(5)

Sep-Oct 2020 /Available online: https://ijels.com/

\section{REFERENCES}

[1] Cao X. Q. \& Gao E. (1987): A Dream of Red Mansions. (X. Y. Yang \& G. Yang, Trans.). Beijing: Foreign Language Press.

[2] Catford, J. (1965): A linguistic Theory of Translation. London: Oxford University Press.

[3] Georges, M.(1963): Theoretical Problems on Translation. Paris: Editions Gallimard.

[4] Whorf, B.L. (1956): Language, Thought, and Reality. Cambridge: The MIT Press.

[5] Xu J. (2009): On Translation. Beijing: Foreign Language Teaching and Research Press. 